\title{
Interfaces, Interphases, and Graded Single Crystals in Dental Enamel
}

\author{
KAREN A. DeRocher ${ }^{1}$, PAUl J.M. SMEETS ${ }^{1}$, Berit H. \\ GOODGE ${ }^{2,3}$, MichaEL J. ZACHMAN ${ }^{2,4}$, PRASANNA V. \\ BALACHANDRAN ${ }^{1,5}$, LINUS STEGBAUER $^{1}$, MiCHAEL J. \\ COHEN $^{1}$, LYLE M. GORDON $^{1}$, JAMES M. RONDINELLI ${ }^{1}$, \\ LENA F. KOURKOUTIS ${ }^{2,3}$, AND DERK JOESTER ${ }^{1}$ \\ ${ }^{1}$ Dept. of Materials Science and Engineering, Northwestern \\ University, Evanston, IL 60208, USA. \\ ${ }^{2}$ School of Applied and Engineering Physics, Cornell \\ University, Ithaca, NY, USA. \\ ${ }^{3}$ Kavli Institute at Cornell for Nanoscale Science, Cornell \\ University, Ithaca, NY, USA. \\ ${ }^{4}$ Center for Nanophase Materials Sciences, Oak Ridge \\ National Laboratory, Oak Ridge, TN 37831, USA. \\ ${ }^{5}$ Dept. of Materials Science and Engineering, Dept. of \\ Mechanical and Aerospace Engineering, University of \\ Virginia, Charlottesville, VA 22904, USA.
}

Dental enamel is one of the most complex, hierarchically structured materials in vertebrates. It is composed of hydroxylapatite crystallites, thousands of which are bundled into rods that are organized in a three-dimensional weave. This architecture provides great fracture resistance and a much-enhanced fatigue life. It has long been known that the susceptibility of enamel to caries, i.e. acid corrosion, is greatly dependent on the presence of magnesium, carbonate, and fluoride ions. However, imaging the distribution of these impurities in enamel or the organic/inorganic interface in the chiton tooth has remained challenging. UV-laser pulsed atom probe tomography (APT), in combination with correlative imaging and spectroscopy techniques, has given us remarkable new insights into nanoscale structure and composition that is integral to the mechanical properties of teeth and their resistance to corrosion..$^{[1,2,3,4]}$ Here, I will report on the distribution of $\mathrm{Mg}^{2+}, \mathrm{Na}^{+}, \mathrm{F}^{-}$, and $\mathrm{CO}_{3}{ }^{2-}$ in the amorphous intergranular phase that cements together crystallites in human enamel. I will further describe highly characteristic gradients of these ions across individual crystallites and discuss implications of these gradients for the mechanical properties of enamel, its dissolution behavior, and enamel formation during tooth development.

[1] Smeets, DeRocher, Zachman, Goodge, Kourkoutis, Joester, Microsc Microanal 2018, 24, 1266-1267. [2] Gordon, Joester, Front Physiol 2015, 6. [3] Gordon, Cohen, MacRenaris, Pasteris, Seda, Joester, Science 2015, 347, 746750. [4] Gordon, Tran, Joester, ACS nano 2012, 6, 1066710675. 